\title{
Sourcing Process - A Supply Chain Management Perspective to Meet Consumer Demand with Special Reference to Solitaire Diamond Brand Sold in Damas Outlets, Dubai
}

Janani Ravinagarajan*, N Anitha† and L Karthikeyan ${ }^{\ddagger}$

\begin{abstract}
Diamond in a supplier's catalogue encompasses a steady price appreciation and less volatility. Strategic sourcing for diamond is based on the assessment of needs and exploration of the legal mining process, and the allied risks. This paper analyses the sourcing process for managing the supply chain with special reference to Damas, Dubai where an organisation has functional expertise at every level but lacks expertise in the value chain.
\end{abstract}

Keywords: Sourcing Process, Supply Chain, Diamond Supply Chain

\section{Introduction}

Damas is a leading international jeweller and a renowned retailer for watch in the Middle East. The company operates as a fully

* School of Commerce and Management, Dayanand Sagar University, Bengaluru, India; dranitha-socm@dsu.edu.in

t School of Commerce and Management, Dayanand Sagar University, Bengaluru, India; jananir-socm@dsu.edu.in

‡ Department of International Business, Sri Ramakrishna College of Arts and Science, Coimbatore, India; lkarthikeyan@srcas.ac.in 
owned subsidiary over 6 countries having 300 retail outlets primarily on GCC location. Damas has grown as an international business, selling global luxury brands to address different consumer segments after it was acquired in April 2012 by a consortium. Solitaire is an in-house brand of Damas with dedicated employees and certificates. Singapore, Hong Kong, India, Italy, and Germany are the major exporters of Solitaire. The Solitaire brand undergoes a 14-point quality check for purity, grading, and certification. It is sold as fixed price jewellery at a competitive price. The brand manager prepares a purchase order based on the sales reports which are compiled globally. The orders are divided based on the demand signals assessed.

\section{1 Solitaire Brand - Demand Signal}

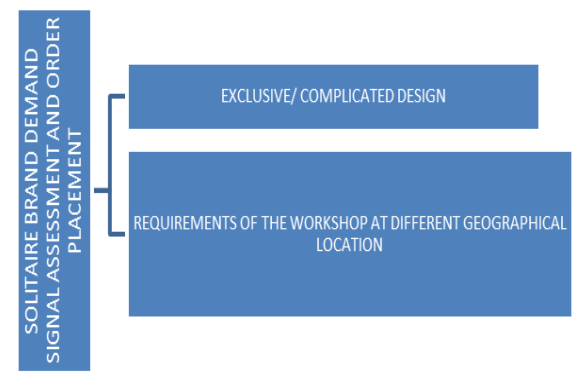

Fig 1: Solitaire Brand - Demand Signal

\subsection{Assessment}

Damas' supply chain management is an integration of sourcing of diamonds from mines and manufacturing factories to the headquarters located at Jumeira Lake Towers, Dubai. Once the diamond reaches the headquarters, it is then bar-coded with a UIN with an ERP system followed by a distribution to a network of stores. After the distribution initiative is made, the outbound logistics team documents and packs according to the customsrequirement of specific countries. The in-house logistics team takes charge of local deliveries for final merchandising in the outlets. 


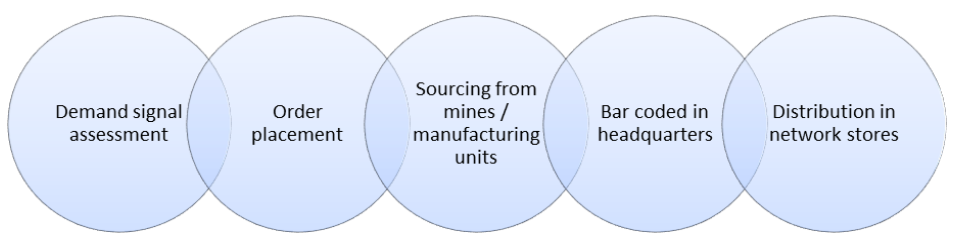

Fig 2: Supply Chain Management of Solitaire Brand Diamonds

\subsection{Need for the Study}

It is important for the retailer dealing with high value consumer products to understand the need for an improvement in the tangible business in the long run. The non-moving inventory in such retailing units are proportionally high and reducing the same would imply better management. When the customer demands are well assessed, it increases the revenue of the company. The paper asserts that the assets and resources could be better utilised to reduce the operational cost. Matching the supply and demand at each stage of the chain allows attaining top brand status thereby being the consumers' first preference. To address the above, the following objectives could be framed.

\subsection{Objectives}

1. to analyse the value chain in order to improve the tangible assets

2. to identify better ways to reduce the non-moving inventory

3. to analyse the effective ways to utilise the assets and resources to match the supply and demand at each stage of the chain

\section{Research Design}

The study was exploratory as well as descriptive in nature. Primary as well as secondary data were used to conduct the research. A quantitative as well as qualitative research was carried out. The questionnaire was framed, and the data was collected through the survey method. It was analysed and the inference has been presented in the article. Data collected through interviews and 
meetings and the findings were presented in the Fishbone analysis, Value Chain analysis, FSN analysis, and Graphs.

\subsection{Limitations of the Study}

Owing to the nature of the data being sensitive, various dimensions could not be taken into consideration. Due to business secrecy, certain information remained undisclosed which may have affected the success of the study. Data accuracy depended on the records and information supplied by the company's officials and due to unavailability of these resources, a comprehensive analysis could not be undertaken.

\section{Review of Literature}

Christopher (1998) defined "the supply chain as the network of organizations that are involved through upstream and downstream linkages, in the different processes and activities that produce value in the form of products and services in the hands of the ultimate customer". When supply chain is integrated to an IT system of a firm, various aspects are to be considered for optimal construction of reliable supply chain (Shapiro, 2001). Considering this becomes important for the retailer who is dealing with high value consumer products to understand the need for an improvement in the tangible business in the long run. For constructing a perceptible supply chain, customer satisfaction and loyalty are assed thus making avenue for profitable growth (Vishwanadham, 1998). When the customer demands are well assessed, it increases the revenue of the company. The communication among the supply chain elements reduces the lead time taken. This enables the assets and resources to be better utilised to reduce the operational cost (Handfield, 1999). Matching the supply and demand at each stage of the chain allows attaining top brand status and being the consumers' first preference (Chopra, 2002). Based on the literature, it is evident that supply chain management has a remarkable role since it not only includes manufacturers, suppliers and customers but also transporters, information technology, warehouses, wholesalers and retailers. It is an inter-disciplinary approach with the combination of technical and relational aspects along with 62 
integration at every level of the organisation. It is evident that any corporate setting needs special attention in the supply chain aspect of management.

\section{Primary and Secondary Activity of the Company}

Sourcing and distribution of the company's products and services is the primary activity of the company. Logistics, operation, outbound logistics, sales, marketing, and service are the primary activities of Damas.

Procurement, technology for improving the sourcing and production process, human resources and the company's administration and management including infrastructure are the supporting activities that make the primary activity possible.

\subsection{Primary Activities}

- The Inbound logistics of Damas includes a strategic inventory control system which consists of receiving, storing, quality check, tagging, and photographing of inventory followed by dispatching it to the respective departments.

- The operations activity of Damas is concerned with making the product appropriate for the consumer by efficiently managing the warehouse operation and the workflow with suitable automated facilities.

- The outbound logistics deals with the responsibility of shipping in line to the legal formalities and documentation, warehousing of finished jewels, material handling, equipment management, and delivering the right product within an appropriate time and cost.

- Sales and marketing include highly motivated and competent sales team by identifying consumer segments and needs, and adopting an effective pricing strategy when handling consumers.

- The customer service of Damas concentrates on responding to customer needs, replacement of parts, warranty, and 
guarantee related services. Each customer complaint is addressed individually.

\subsection{Secondary Activities}

- Research and Development is to focus on adopting technology and acquiring knowledge of tools and machinery to address situations. Positive collaboration between departments and effective ERP (Microsoft Dynamix AX for retail), professionally qualified personnel and state of art facility are the fine-tuned effects of research and development in Damas.

- The information system used in Damas jewellers integrates the information all across the departments, links the information to manufacturing, finance and HR department, processes order entries, tracks events across the company, plans future activities based on the events, and also supports in analysing the trends to improve future performance.

- The Human Resource of Damas focusses on quality work environment, and motivates, trains, and appraises the employees periodically. It also concentrates on training and awarding the employees periodically.

- General management, finance, and accounting involve an effective planning system, anticipating and acting to the key environmental factors, trends, and events. It also concentrates on the ability to obtain funds at low cost for both working capital and capital expenditure needs. It also aims at enhancing the value chain by good coordination and integration.

\section{Value Chain Analysis}

Value chain analysis is conducted to find the effectiveness of the primary and secondary operation of the company in the following five steps: 
Step 1: Initial desk research of targeted interviews were conducted to find the structural/dynamic factors affecting the supply chain comparing it with the data available in the industryspecific journals, newsletters, imports/exports data consumption summary and so on.

Step 2: Value chain mapping gave a visual depiction of the basic structure.

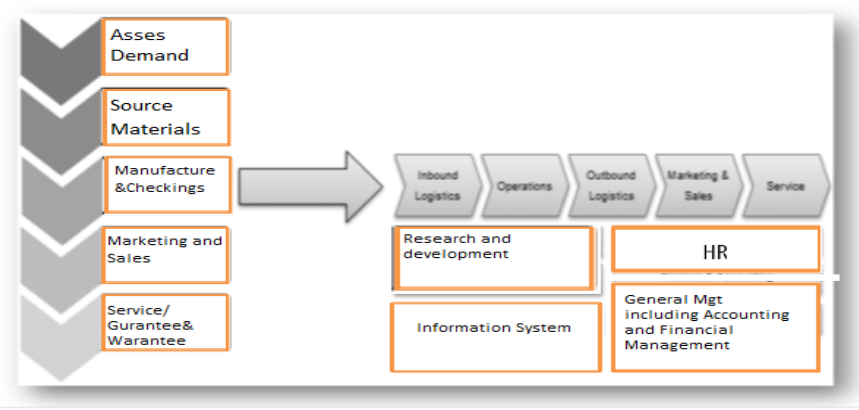

Fig 3: Value Chain Mapping

Step 3: The following areas were identified on the ground that value chain framework can be generated to frame systematic chain level issues with attention on firm-level problems.

Step 4: The next step was undertaken which involved scrutinising the findings of value chain analysis.

1. The end to end process of Damas was understood after several rounds of discussions and observations.

2. Damas had functional experts but not value chain experts. 
3. Damas jewellers struggled with the speed of converting data into knowledge.

4. Damas jewellers had problems of ordering, replenishing, and delivering to retail stores as there are various activities in the supply chain. Inefficiencies in the entire system of the source to self were identified.

5. Many key personnel were responsible for various aspects of the value chain but none were accountable and responsible end to end.

6. Damas has an excellent quarterly incentive wherein performers get individual cars as rewards.

7. 'Just in time' approach is not followed by Damas which according to the study could improve the ROI by reducing the process inventory and associated carrying cost.

8. EDI (Electronic Data Interchange) with supplier and customer was not available. This, if present, could ensure the authenticity of every detail.

Step 5: The next step involved the implementing of value chain development.

Damas can implement the necessary programme by direct intervention or facilitation.

\section{Fishbone Analysis}

Fishbone Analysis is a cause and effect analysis. The following are steps that can be taken to do the fishbone analysis.

1. Identifying the problem and causes by writing in detail.

2. Scrutinising the major factors involved.

3. Brainstorming and arriving at possible causes.

4. Analysing the diagram with possible parameters.

The major problem identified in Damas was "inaccurate data for any records to asses demand".

\section{Identifying Causes}

(a) Diamond scarcity and problems in sourcing 
- Same specification across the globe

- Damas doesn't buy low-quality diamonds

- Diamonds are rare and the wholesaler favours cash paying retailers

- Wholesalers control the market

(b) Environmental

- Legal formalities in sourcing

- Limits in sourcing

(c) Equipment

- Mounts and designs are manufactured in-house

- Occasional import

- Manufacturing takes a long time in case of bulk manufacturing

- Diamonds are set manually in the mounts and are not done by machines

(d) Process

- Diamonds are not fast-moving goods and the existing inventories hamper new purchases

- Purchasing is a tedious and time- consuming process

- Control on allocation and distribution

- Making the right product available at the right time for the right person

- Date capturing in ERP includes barcoding with unique numbers for each solitaire diamond 


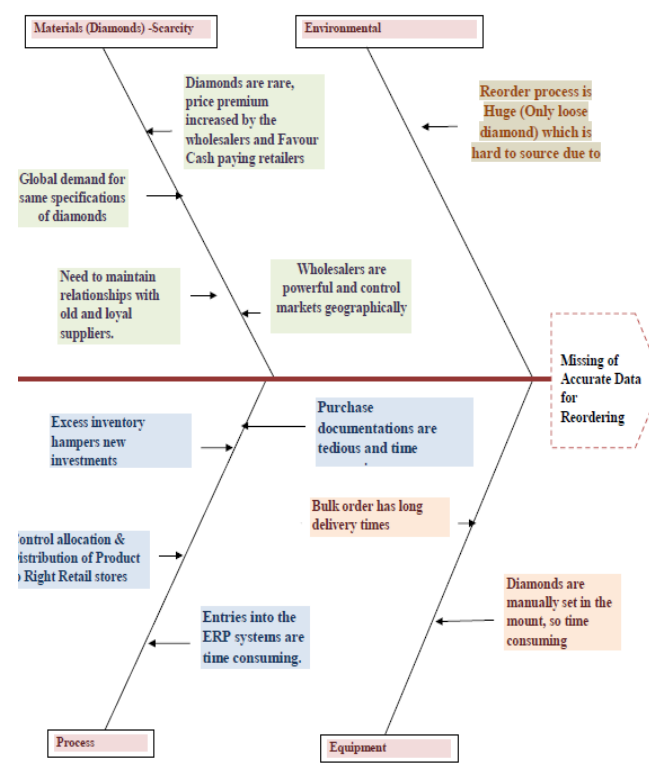

Fig 5 Fishbone Analysis of Damas' Problem

\section{FSN Analysis}

Fast, slow, and non-moving item analysis is done in order to provide assistance. That includes the following:

- Identify regular review items

- Surplus items whose stocks are higher than their rate of consumption

- Non-consumed stocks available in the inventory is classified as non-moving 


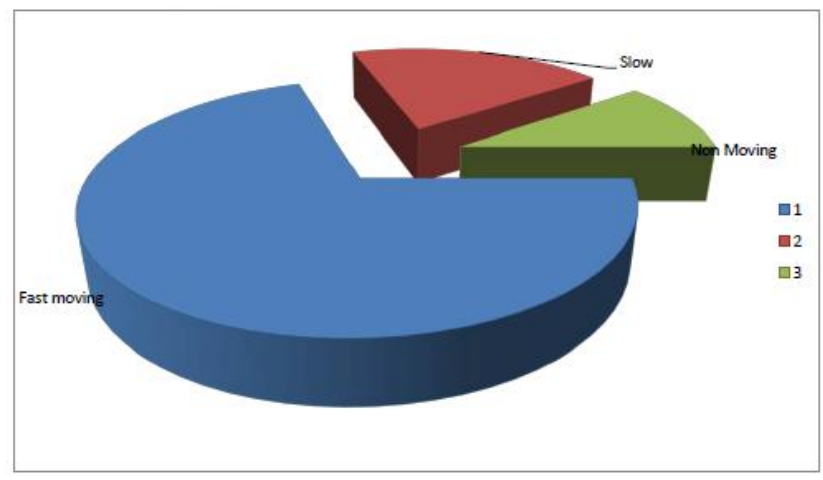

Damas has varieties of stocks ranging from fast moving to nonmoving. Both categories are stored in the same stores which occupy retail space. This analysis helped identify the non-moving items which are not being sold as well as the surplus items whose stocks are higher than the rate of sales. Solutions can be provided for this like keeping the non-moving items to the central division in headquarters, to be used during the $50 \%$ sale.

\section{Quantitative Analysis}

The customers of Damas were given a set of questions to find their taste and assess the pattern of demand. Questions were replied by the Damas customers of Abu Dhabi, Sharjah and Dubai.

Table 1 Age group of consumers

\begin{tabular}{lllllll}
\hline Age Group & $10-20$ & $21-30$ & $31-40$ & $41-50$ & $51-60$ & $60+$ \\
Number of Responses (23) & 0 & 10 & 9 & 4 & 0 & 0 \\
\hline
\end{tabular}

- Solitaire clients are generally aged between 21-30

- They are young, independent, and can afford it themselves 


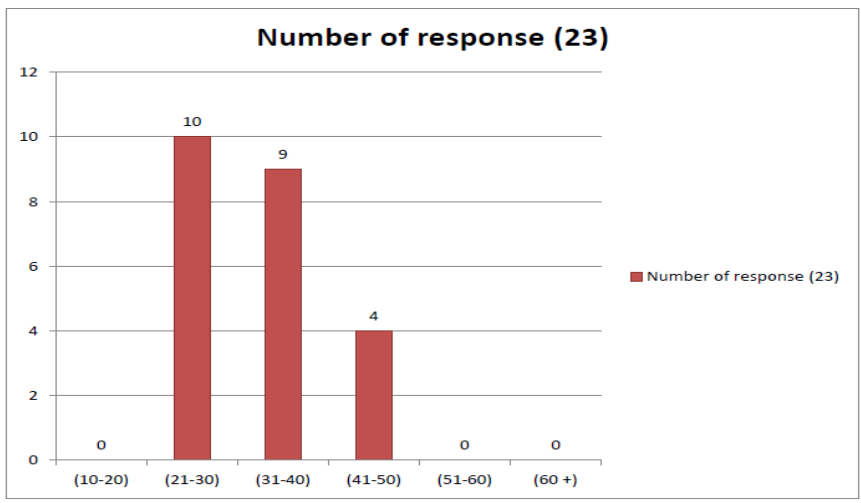

Table 2 Response Sheet for Analysing whether Purchase is made for Individual Use or Gifting

\begin{tabular}{lllllll}
\hline For Whom & Self & Wife & Fiancée & Daughter & Mother & Friends \\
\hline $\begin{array}{l}\text { No. of response } \\
(30)\end{array}$ & 15 & 9 & 2 & 2 & 1 & 1 \\
\hline
\end{tabular}

The results depicted that while $50 \%$ of the customers bought Solitaire diamonds for themselves, $30 \%$ of them would buy it for their wives.

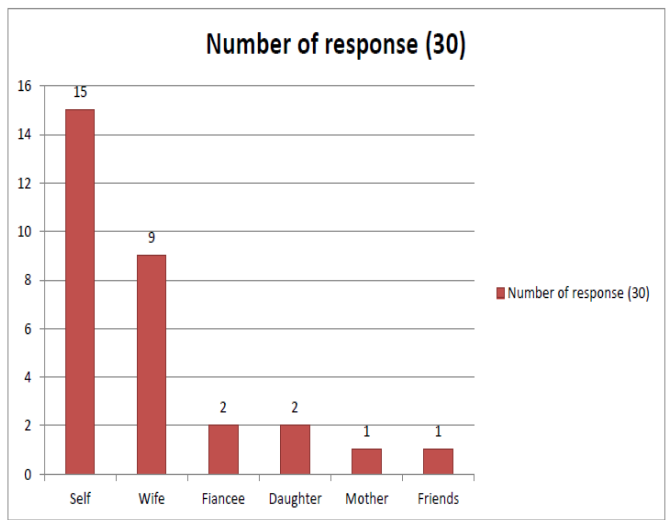

Table 3 Response Sheet for Analysing the Purchaser of Diamond

\begin{tabular}{lllllll}
\hline Purchaser & Self & Husband & Finance & Parents & Friends & Others \\
\hline $\begin{array}{l}\text { No. of } \\
\text { respondants (25) }\end{array}$ & 11 & 3 & 3 & 5 & 1 & 1 \\
\hline
\end{tabular}


Janani et al.

$45 \%$ of the buyers bought it themselves, whereas $12 \%$ of the diamonds were brought by husbands, and $12 \%$ by fiancé (groom) for their to-bebrides.

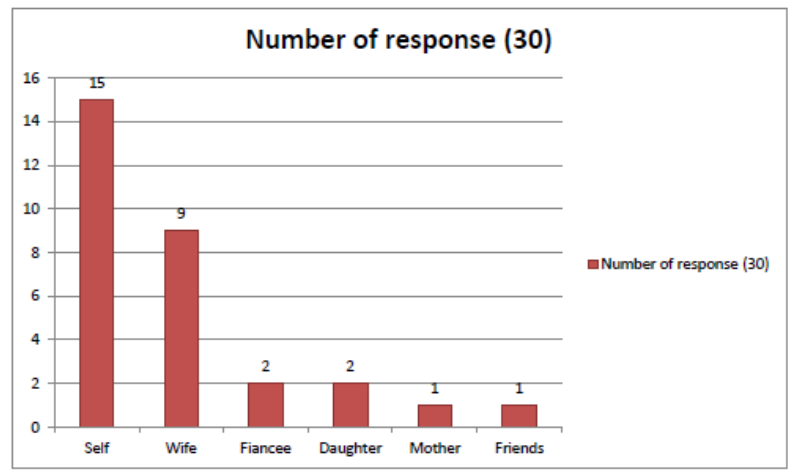

Table 4 Preference for Purchase of Solitaire Diamond - Ring, Pendant or Earring?

\begin{tabular}{c|l|l|l|l}
\hline Item & Ring & Earring & Pendant & Others \\
\hline No of respondants (41) & 16 & 12 & 12 & 1 \\
\hline
\end{tabular}

While $40 \%$ of respondents preferred rings, 30\% preferred earrings and pendants at $30 \%$. The other $20 \%$ were mostly related to the preferences of parents.

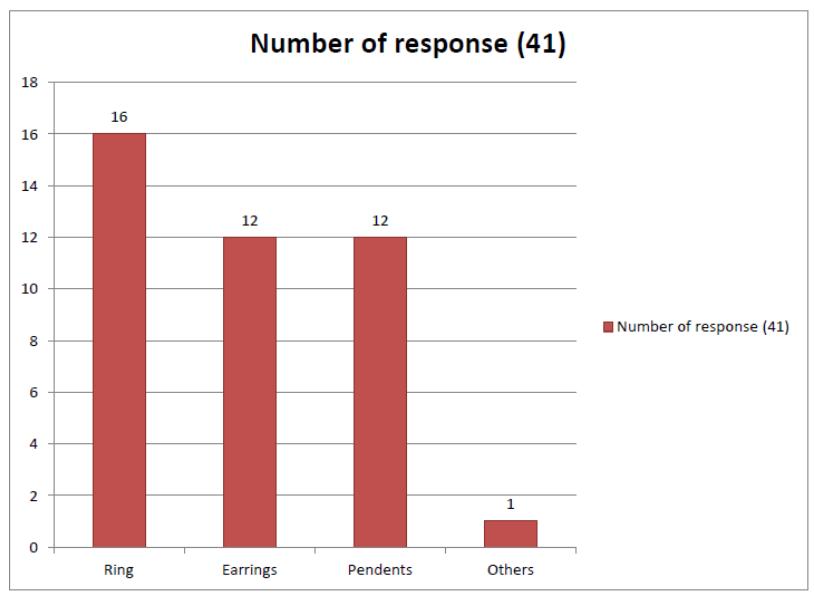


Table 5 Preference of Metals with Solitaire Diamond

\begin{tabular}{l|c|c|c|c}
\hline Metals & Platinum & White gold & Yellow gold & Rose Gold \\
\hline No of response (28) & 4 & 13 & 9 & 2 \\
\hline
\end{tabular}

The results show that while white gold is preferred by $42 \%$ of the respondent, $32 \%$ liked yellow gold, and 14\% preferred Platinum.

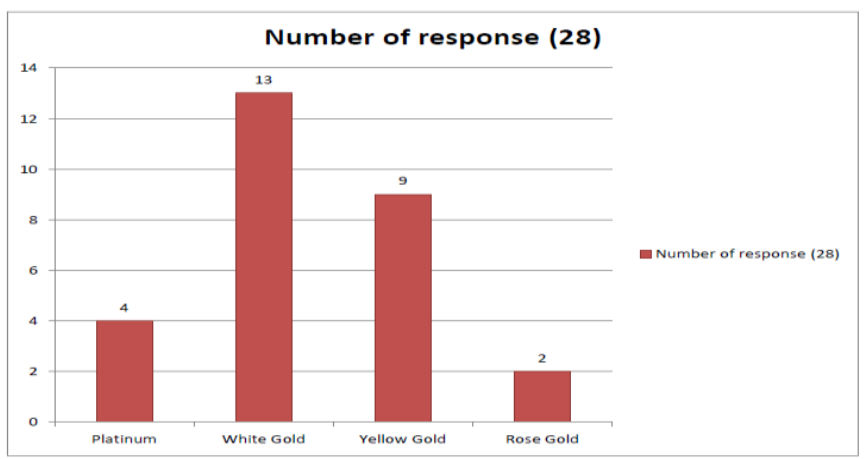

Table 6 Quality Expectations During Purchase of Solitaire Diamonds

\begin{tabular}{lllllll}
\hline Quality & Flawless & VVSI & VVS2 & VS1 & VS2 & Others \\
\hline No. of responses (27) & 11 & 7 & 1 & 4 & 1 & 3 \\
\hline
\end{tabular}

While flawless diamonds are preferred by $40 \%$ of the respondents, VVS1 is liked by $25 \%$ of the people where $15 \%$ likes VS.

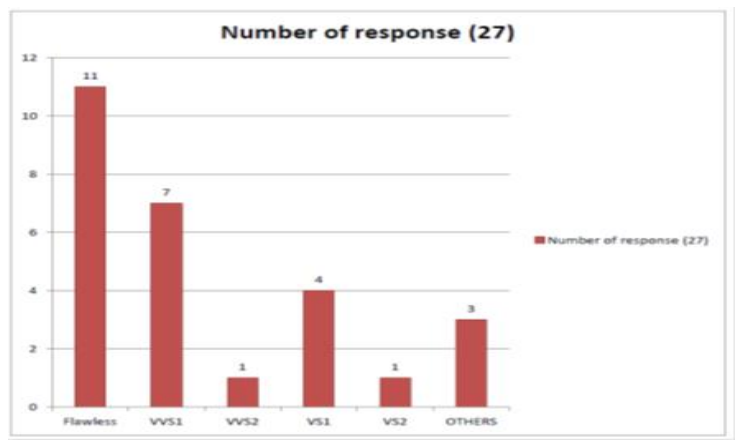


Janani et al.

A SCM Perspective to Meet Consumer Demand

Table 7 Price Range for Solitaire diamonds

\begin{tabular}{l|c|c|c|c|c|c}
\hline Expected Price & $\begin{array}{c}1500- \\
2500\end{array}$ & $\begin{array}{c}2500- \\
5000\end{array}$ & $\begin{array}{c}6000- \\
12000\end{array}$ & $\begin{array}{c}15000- \\
24000\end{array}$ & $\begin{array}{c}25000- \\
28000\end{array}$ & $\begin{array}{c}35000 \\
+\end{array}$ \\
\hline $\begin{array}{l}\text { No of } \\
\text { response (27) }\end{array}$ & 4 & 5 & 9 & 4 & 5 & 0 \\
\hline
\end{tabular}

While $18 \%$ prefer the high-end Solitaire ranging from 25,000-28,000, $33 \%$ customers prefer Solitaires within the price range of $6000-$ 12,000 .

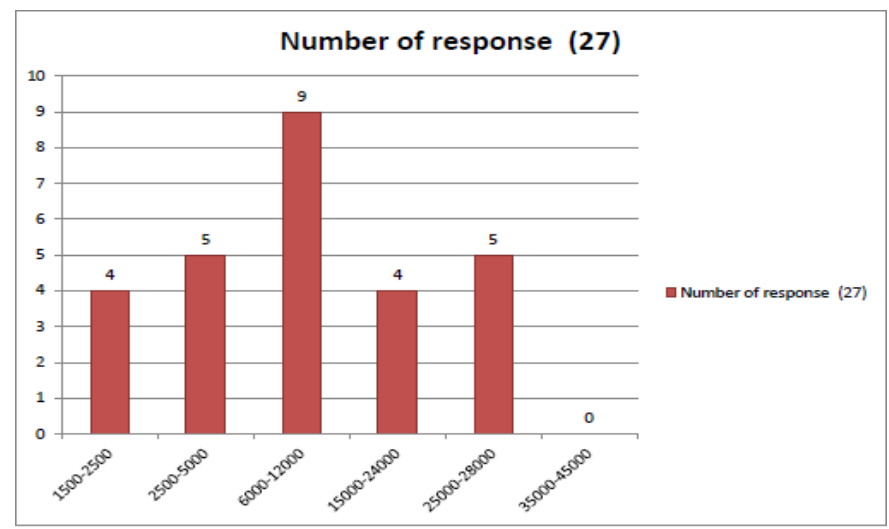

Table 8 Response to the Question - "Solitaire Diamond is the best fit in terms of - classic, fancy, simple, complicated, custom made or brand copying?"

\begin{tabular}{l|l|l|l|l|l|l}
\hline Design & Classic & Fancy & Simple & $\begin{array}{l}\text { Brand } \\
\text { Copy }\end{array}$ & Complicated & $\begin{array}{l}\text { Custom } \\
\text { made }\end{array}$ \\
\hline $\begin{array}{l}\text { No of } \\
\text { response } \\
(29)\end{array}$ & 13 & 8 & 4 & 0 & 2 & 2 \\
\hline
\end{tabular}

Respondents asserted that the classic solitaire design is the major attraction as $45 \%$ of respondents seek for them. 


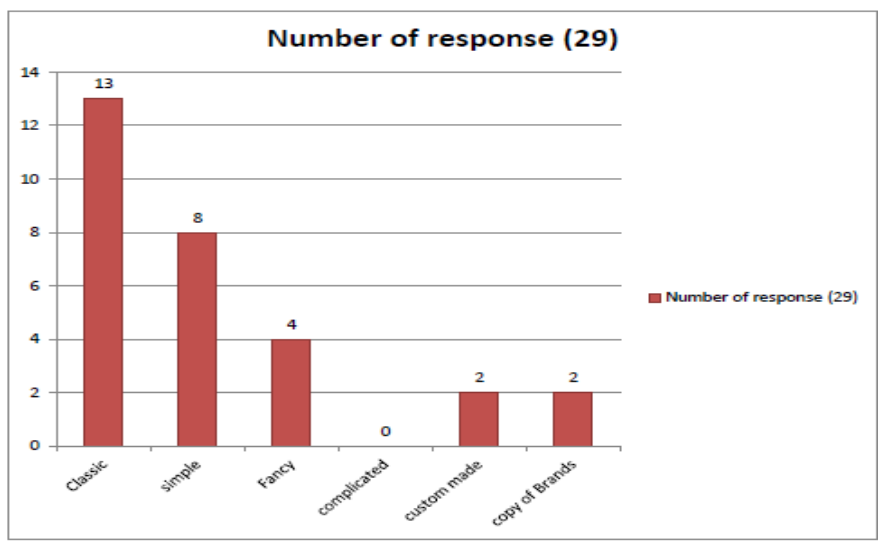

\section{Conclusion}

Damas Jewellers have been managing the process efficiently. The functions of every department are clearly set. Streamlining of certain processes can reduce the stock of non-moving goods. Damas can stock such items in the headquarters and can reintroduce it during the $50 \%$ sale seasons. This will enable Damas Jewellers to meet the demand of consumers more effectively by supplying more choices for decision making. Damas shares an excellent relationship with suppliers across the globe. Sourcing the items according to the demand creates value addition as sometimes orders by customers are of huge value. Moreover, stock maintaining techniques such as $\mathrm{ABC}$ analysis and inventory management techniques can be introduced in diamond warehouses. In addition, efficiency and working system though well-defined should be aimed at creating a value chain insisting on responsibility and accountability of the same which could enhance the efficiency of the supply chain management systems at Damas. 
Janani et al.

A SCM Perspective to Meet Consumer Demand

\section{References}

Chopra, S., \& Meindel, P. (2002). Supply chain management: strategy, planning and operation. Prentice Hall of India.

Christopher, M. (1998). Logistics E supply chain management: strategies for reducing costs and improving services. Pitman Publishing: London.

Handfield, R. B., \& Nichols, E. L. Jr. (1999). Introduction to Supply Chain Management. Prentice Hall.

Shapiro, J. F. (2001). Modeling the supply chain. Duxbu Thomson Learning.

Viswanadham, N., \& Narahari, Y. (1998). Performance modelling of automated manufacturing systems. Prentice Hall of India. 